\title{
The Metabolic Core of Environmental Education
}

\author{
Ramsey Affifi ${ }^{1}$
}

Published online: 12 November 2016

(C) The Author(s) 2016. This article is published with open access at Springerlink.com

\begin{abstract}
I consider the case of the "simplest" living beings—bacteria—and examine how their embodied activity constitutes an organism/environment interaction, out of which emerges the possibility of learning from an environment. I suggest that this mutual coemergence of organism and environment implies a panbiotic educational interaction that is at once the condition for, and achievement of, all living beings. Learning and being learned from are entangled in varied ways throughout the biosphere. Education is not an exclusively human project, it is part of the ancient evolutionary process of elaborating and diversifying the relational possibilities inherent in metabolism that has brought forth our diverse and flourishing world. Abstracted from context, "education" appears as a set of ways in which humans actively engage and take responsibility for the learning outcomes of relationships with each other. Insofar as we consider this distinction absolute rather than a performed construct to be assessed by its consequences, we blind ourselves to the educative dimension of other species as well as our many miseducative engagements with them. If learning processes are inherent and constitutive of ecological communities, education theorists should devote their pedagogical sensitivities and insights to the crucial challenge of developing educative sustainable human-nature relations.
\end{abstract}

Keywords Enactivism - Autopoiesis - Environmental education · Interspecies education · Bacteria learning · Posthumanism 


\section{Introduction}

In the 21st Century, life on Earth faces widespread and increasing ecological threats, including mass species extinction, pervasive habitat destruction, rampant pollution, and global warming. Sadly, these facts need no citation. This destruction results from the structure and operation of modern societies, with education systems likely at once integral in reproducing such societies and a possible means for reconstructing them. Philosophy of education has an essential role by, in part, helping people reinterpret the scope, meaning, and responsibilities of education such that it can be re-imagined for more ecological ends. This paper develops one such reinterpretation by considering the biological foundations of education. My aim is to scaffold readers out of a view that "education" is a uniquely human endeavour. In my view, this is an untenable vestige of a dualistic metaphysic that sees humans as minded and the rest of nature as mechanical. ${ }^{1}$ I believe a closer reading of contemporary biology challenges this dichotomy with widespread implications for how we think about schools, pedagogy, buildings and infrastructure, conservation programs, and biological research. Biological theory now suggests that educative relationships broadly construed are necessary and constitutive for the ongoing flourishing of all life forms. I develop this suggestion by focusing on what is generally seen as the "minimal case" of life, the single-celled prokaryotic species known as bacteria. After considering how learning and being learned from are essential to bacterial metabolism, I argue that all organisms are therefore engaged in what prefigures, as the ground, condition, and alternative manifestations, the sorts of processes we think about when considering "education" in the human-human domain.

The path I'll tread draws from the "enactivist" approach to biology which rose to prominence through shortcomings in disembodied "representational" theories of mind. ${ }^{2}$ Against the view which sees cognition as a process of manipulating symbols inside the brain or computer, ${ }^{3}$ enactivists develop a concept of cognition grounded in active engagement in the world. Several themes distinguish enactivism from the symbol-processing computational models of its ancestors. Fundamentally, enactivism sees cognition as situated and embodied, often non-symbolic, and based on the cognizer's needs and history of interactions with its immediate material and social worlds. Prominent educational theories focussing on the dynamic, learner-directed, and situated character of learning are important forerunners and allies of modern enactivism. Historically, this includes Deweyan interactionism, ${ }^{4}$ Bruner's "learning by doing", 5 Piaget's constructivism, ${ }^{6}$ Vygotsky's social constructivist interaction, ${ }^{7}$ but it also shares many of the premises of more contemporary theory, including situated learning, ${ }^{8}$ "shared action" models, 9 and "radical embodiment". ${ }^{10}$ However important critiques of learning as "knowledge

\footnotetext{
1 Affifi (2011).

2 Varela et al. (1993).

3 Such as we find in Fodor (1990) and Newell and Simon (1972).

4 Dewey (1916).

5 Bruner (1961).

6 Piaget (1974).

7 Vygotsky (1978).

8 Lave and Wenger (1991).

9 Sumara and Davis (1997).

10 Joldersma (2014).
} 
acquisition" or "information processing" have been in education theory, enactivism is not merely or even mainly an educational theory. Many enactivist philosophers, psychologists, and biologists are concerned with articulating a likely isomorphism between mind and life, and with understanding the different manifestations, and different effects, of mentality throughout the biosphere. ${ }^{11}$ Education theorists of an enactivist bent may not be aware of these discussions or of what implications they may have for how we conceive and conduct our profession.

Enactivists investigating the biological world tend to share the view that mind and life are co-extensive ${ }^{12}$ even while they all maintain the view that the types or complexities of mind certainly vary. ${ }^{13}$ Likewise, while none are panpsychists in the sense that they do not attribute mind to inanimate matter, neither are they vitalists who attribute mentality to some ineffable substance that pervades the living. Instead, an enactivist would likely argue that mind is an embodied process or activity that emerges given certain types of organization and that this type of organization emerges through processes that manifest and define life. In enactivist accounts, the brain is not the location of cognition nor is it generally thought of as a necessary organ for it to occur. Cognition is the process of the active embodied organism, which is assisted in its goal directed activities by the organism's various organs, which may or may not include brains. Rather, cognition is rooted in the sensorimotor coupling between organism and environment that occurs through the process of life. ${ }^{14}$ Unlike representationalist accounts, which claim that minds access representational constructs, enactivists follow Merleau-Ponty in asserting that subjectivity and world are "co-dependent and inseparable", ${ }^{15}$ emerging together through the sensorimotor integration of organic life. Enactivists also often maintain that distinction-making is crucial in this coupling process (for example, for Jonas, it is the constituted distinction between being and not-being, for Bateson it is information as 'the difference that makes a difference,' while Maturana and Varela speak of the act of "observation" which defines and separates an object against a background). Again, this distinction-making is an active process: a particular distinction is not a "representation" of some external reality but constituted by the needs and organization of the organism's embodied adjustments to its world and enacted through how it responds to the distinction(s) it has constituted. The enacted world does not appear therefore as a neutral field. It elicits responses according to how it appears for the organism. Because distinction-making is driven by an organism's history and needs, distinctions have a significance, and enact a semiotic domain of goals, valence, meaning, threats, possibilities, and other qualities in the world. ${ }^{16}$ For instance, bacteria distinguish sugar-like molecules from the generic biochemical soup within which they swim. This distinction is possible through their metabolic processes, which continually generate the possibility of interacting with sugar as affording food, but the distinction is also necessary for continued metabolism because the organism would die without it. Since being a nutrient is not inherent in the physicochemical nature of the world, it is, as Thompson points out "a relational feature". ${ }^{17}$ The metabolizing organism enacts an

\footnotetext{
11 For a recent sampling, see Stewart et al. (2014).

12 Thompson (2007).

13 Jonas (1966), Maturana and Varela (1980) and Bateson (1979).

14 Maturana and Varela, Autopoiesis; Heschl (1990).

15 Zahavi (2005).

16 Merleau-Ponty (1963).

17 Thompson, Mind, 74.
} 
environment to which it relates differentially and where much phenomena is not afforded as significant. And this goes without the need of transforming the world into symbols and rules for their operation.

My title draws provocatively from Jonas, ${ }^{18}$ who uncovered how metabolism could not be considered as a purely physicochemical process without misunderstanding the nature of life. Metabolism, for enactivists, is where enaction begins. ${ }^{19,20}$ Metabolism does distinction-making, first by enacting the distinction between organism and world, and thereafter by enacting distinctions within each that enable the organism to continue to flourish. It is in metabolism that we have the dynamic and developmental coupling between an organism and its environment, a life-driven process that creates relationships and organized chains of interlinking complexity otherwise absent in the universe. In this paper, I focus on learning and defend the claim that learning is the process of changing distinctions ${ }^{21}$ that is both the condition and effect of the metabolic organization of all life forms down to, and including, single cells. Even bacteria seem to alter the distinctions they enact, making them either finer or coarser in ongoing response to the effects of former distinction-making activities, in a process motivated by the organism's ongoing interests and the world that emerges as affording these interests. Moreover, the metabolic process provides a bacterium with an openness to its world such that it can also learn from (and be learned by) other bacteria and other organisms.

Changing distinctions can occur through either drawing a more precise distinction or relaxing an old one. "Synthesis," "generalization," "metaphor," and "associative learning" rely on the loosening of distinctions such that various things, once held as separate, are now put into relationship with one another. Human learning and teaching are contingent from and grow out of the openness to the environment constituted by metabolism.

\footnotetext{
17 Thompson, Mind, 74.

18 Jonas, Life.

19 Thompson, Mind.
}

20 Metabolism, cognition, and autopoiesis were considered isomorphic early on by Maturana and Varela (1980). There has since been some debate about the relationship between these terms. Among those who agree that all three are a minimum condition for life, some claim that metabolism and autopoiesis are essentially the same but that these refer only to autocatalitic systems which have now been reproduced artificially in the laboratory (van Duijin et al. 2006). Such an argument suggests that in addition to metabolism, cognition in the form of adaptive sensorimotor coupling of an organism with its environment is also needed. Varela, when considering tessellation automaton, seemed to drift towards the view that autopoiesis, but not cognition was necessary and sufficient for life (Luisi and Varela 1989), while still maintaining that cognition was present along with autopoiesis in all biological life (including bacteria). Bitbol and Luisi (2004) argue that metabolism necessarily means a selective interchange between a constituted entity and its environment, which is inherently an adaptive cognitive process making (their understanding of) autopoiesis a necessary but not sufficient condition for life. At root, seems to be the issue as to whether metabolism is merely homeostatic or whether it is also adaptive, and whether something can be homestatic for long without having adaptive strategies available. Thompson (2007) pointed out that as long as existing living things (as opposed to experimental constructs) are autopoietic and cognitive, then it makes little theoretical or empirical difference whether or not we merge the terms. I will follow Bitbol and Luisi (2004) here and use the word 'metabolism' to refer to this self-producing process that is necessarily cognitive and autopoietic. I will, however, discuss 'learning' instead of cognition because my interests stem from the way in which organisms constitute and respond to novelty, and how humans conceive and take responsibility for these processes. I also think the word "cognition" tends to be misleading insofar as it suggests a narrow concept of epistemology centered around processing the validity of knowledge propositions whereas I think the enactivists see the cognitive activity of organisms as primarily about the enacting of an organism/environment relationship of qualities: significations, valence, attractions, repulsions, uncertainties, etc., from out of which propositional knowledge only sometimes emerges.

21 Bateson (1972); Bateson, Mind and Life. 
However, we are not alone on this account. Indeed, all organisms, through their diverse forms, behaviours, and manners of transacting, have diversely elaborated the nature of metabolism over the course of biological evolution, and with it the types and tempos of learning that metabolism enables and depends upon. If learning is ubiquitous across the biological world, then what are the effects of treating other species rigidly and mechanically when they are neither rigid nor mechanical? What do we miss out on in our human but also in our interspecies pedagogical relations when we assume that humans alone are gifted with the capacity for learning, generating novelty, and breaking out of the confines of genetic (or some other) determinism?

I focus on the case of learning in a single-celled organism because I think the project of gradually expanding a circle of educational considerability outward, first to include primates and dolphins, and so on, is counterproductive as it runs the risk of reifying (a humansupremacist sort of) anthropocentrism and dualism at the same time. This is so because organisms are invariably judged against some ontologically remarkable quality that humans are said to have. ${ }^{22}$ I believe that a wholesale re-examination of the scope and roles of learning in biological and ecological systems is essential for cultivating more attentive and responsive attitudes towards other species. Breaking down the line between the fields of education and biology does not mean applying sociobiological reductions nor promoting unwarranted anthropomorphisms. Humans, like all species, are unique in their manners of interacting and learning, and sensitive intra-human pedagogies are not discounted here. But what an enactivist view of learning does is suggest a deep continuity in the open-ended and relational development of all organisms, which are precisely those aspects of life that education engages in humans. Whether and how we take responsibility for such a pedagogy affects how we, and other species, will continue to interact with one another, so it is at once an educational and an ecological issue.

\section{Metabolism's “Ontological Reversal”}

Textbook-style definitions of metabolism refer to it as the necessary exchange and transformation of material between an organism and its environment such that the identity of the organism is maintained. It is seen as the process whereby the organism acquires and processes essential inputs and expels unwanted outputs. From a mechanical point of view, the metabolic activity of a cell is assumed to be a giant biochemical device. But this metaphor is incomplete for several reasons. The process of exchanging material between organism and environment does not occur in a way that is similar to any machine or device that we have manufactured and, in fact, reveals the unique ontological nature of the living organism in a number of surprising ways.

First, as Jonas (and later Maturana and Varela) noted, metabolism does a great deal more than acquire, transform and discard chemicals. Were it simply about such chemical transformations, metabolism would not be different from an engine, which takes in fuel and turns it into power and exhaust products. An organism's metabolism, however, is engaged in the very construction of the form of an organism. Its capacity to metabolize is itself dependent on the fact that its metabolism includes also the regeneration of its very organization. For this reason, while the form of the organism survives, its particular biochemical makeup is constantly changing, as its parts are made and remade continuously. In Jonas' words, “[m] etabolism thus is the constant becoming of the machine itself—and this

22 Weston (2004). 
becoming itself is the performance of the machine: but for such performance, there is no analogue in the world of machines." ${ }^{23}$ While all other forms in the universe may be merely products of our perception or mere aggregates (like rocks, where a description of their dynamics is adequately explained without resorting to their form), the same cannot be said of living beings whose parts do not explain but are instead ordered and structured, and therefore to be explained by the needs of the whole. In other words, according to Jonas there is an "ontological reversal" between organization and components that occurs in the metabolic structure of living organisms such that the organization is essential and the particular components making up the structure are accidental. ${ }^{24}$ The second reason why the mechanical point of view is incomplete is that what counts as an input and how it functions as such is constituted by the organism as well. The environment is acted upon according to valence and significance for the organism. This aspect is crucial to this paper's argument but will be discussed later, in the context of difference-making and learning.

Metabolism, at once producing and produced by the organization of the biological system embedded in its environment, creates for Jonas a number of other "antimonies" or "dialectics" that immediately distinguish even the most rudimentary organism causally, epistemologically, and ontologically from the physicochemical domain of interactions dominated by efficient causality. I will go over some of these briefly because they set the context for understanding the "ontological reversal" that Jonas suggests. First, the emergence of a metabolic organization (or, as he calls it, "form") implies an isolation and separateness from a world because the organism is able to maintain its form despite the vicissitudes of an environment that its boundedness constitutes as "other" than it. This polarity between a primordial self and a primordial environment marks the beginning of what Jonas calls a "needful freedom" and of "relation." The term needful freedom is taken to stress the fact that while a certain independence is achieved by the perpetual sustenance of this form, it is an independence that paradoxically requires a constant interchange with the environment from which it has separated itself. ${ }^{25}$ By "relation," Jonas wants to contrast purely physical interactions with the sorts of engagements an organism participates in through enacting a meaningful world of valence and signification, attractions and repulsions. Thus, because of this opening up of relatedness, the isolation of metabolism simultaneously implies an increased intimacy because the organism "becomes the subjectpole of a communication with things" ${ }^{26}$ that are not it. Both of these paradoxes are present in the metabolism of a single-celled organism but diversify and, for Jonas intensify, as evolution produces increasingly individuated forms throughout the kingdoms of life. Second, Jonas observes that space and time are constituted for the simplest of life forms in a way that is different from the physicochemical world. The active organism interacts in an environment that is structured according to what phenomenologists refer to as a "horizon." Instead of space extended symmetrically from any and all directions, as is implied by a physicochemical conception, a spatial environment with a horizon appears with the organism at its center and extended outward graded by the organism's needs and concerns. In other words, we have not a "spatiality of position, but a spatiality of situation". ${ }^{27} \mathrm{~A}$ horizon of time is also thrown open: the striving to meet goals places a teleological matrix

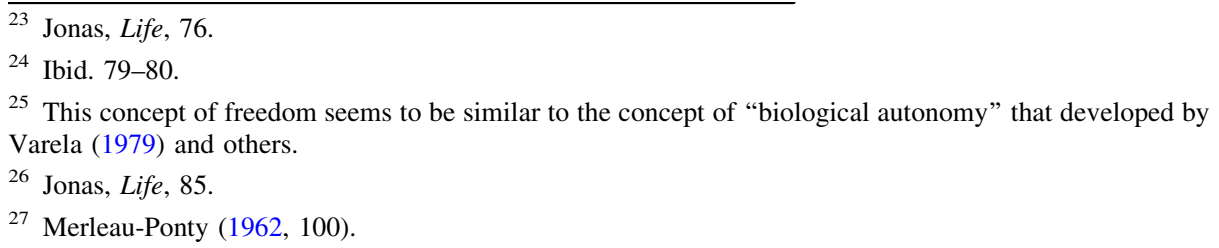


overtop the physicochemical world, with the moment preceding assessed against what is anticipated in the next. Thus, time is not a geometrical line but a continuous "now" with a past and a future that contextualize what is happening and what can be done. This spatiotemporality is again visible in the behaviour of an $E$. coli bacteria swimming up a sugar gradient towards a food source. Because swimming towards the sugar requires that the bacteria compare the sugar concentration at two different spatial and temporal locations, the bacteria's world emerges with it as the centre around which the gradient is presented. And again like "freedom" and "relationship", for Jonas, this initial opening up of a spatiotemporal horizon in the single-celled organism is elaborated upon and increased in depth and significance as life flourishes and complexifies.

As Jonas pointed out, metabolism constitutes the most fundamental existential distinction, which is the separation of organism and environment. Maturana and Varela ${ }^{28}$ explain that the circular and homeostatic organization of an organism gives it an identity against a context with which it must continually interact in order to retain the organization. The split between organism and environment interrupts and gives new interactive potential to the otherwise undifferentiated physicochemical world from which it came. In other words, without life, neither "environment" nor "organism" exist, but dynamically coemerge. ${ }^{29}$ It seems that this distinction is both ontological and epistemological. It is epistemological in the sense that the organism is engaged in (embodied) modelling or interpreting. But it is an epistemological distinction that has effects in and on the world, including importantly the effect of maintaining its very existence. The relationship between epistemological constructions and ontological emergence is therefore dynamic and dialectical in living organization. It is only by virtue of the form of the living cell that it is able to draw important distinctions that in turn maintain its form.

The organism/environment interaction continually manifested by the process and product of metabolism is therefore not dualistic in the sense that there are two separate kinds of interacting things in the world itself, even though the organism may enact some sort of dualism. It is also, I would add, not simply a matter of an organism creating an inner/outer distinction. Borrowing from evolutionary developmental ("evo-devo") theory, I think we can add to the enactivist analysis the fact that organisms can compare and draw distinctions in both their internal and external states. According to evolutionary biologist West-Eberhard, ${ }^{30}$ organisms have both an internal and an external environment. It is because a bacterium can register differences between its internal states that it seeks food when not satiated. It is because it can register differences in its external states that it can swim towards a source of sugar (it interprets a gradient by comparing the differences in sugar concentration in the water at two different points in time). ${ }^{31}$

\footnotetext{
${ }^{28}$ Maturana and Varela, Autopoiesis.

29 Thompson, Mind.

30 West-Eberhard (2003).

31 According to evo-devo theory, the organism qua organism actively accommodates what it interacts with, whether this be its own genes, metabolites, or other organisms in the terrain it is negotiating. Although some of these interactants are constituted as "internal" and others as "external" they are in fact in semantic coordination because a change in "outer" experience is a change in "internal" constitution as they continually circulate and correlate with one another through ongoing sensorimotor activity. For this reason, evodevo theory has made significant strides in overcoming the nature/nurture dichotomy (West-Eberhard 2003; Oyama 2000). If we examine the genetic aspects of organism constitution, we again see that both the internal and the external environment appear in part as they do based on which genes are turned on and off at a given point. But the organism's response to the significance of how it interprets these environments (i.e. how it draws distinctions within and between these states) also switches on and off its genes. The organism/
} 
An organism enacts its metabolism in a world of flux and this world elicits certain activities rather than others based on its history, needs, and the possibilities available through the sensorimotor features of its form. Those external things that are needed (or not) for its ongoing perpetuation are presented as such, and an environment is set in relation to the organism that is quite different from the interactive domain of the purely physicochemical. In short, with metabolism we have what Thompson calls "the dynamic coemergence of an individual and an environment." It is the burden of the rest of the paper to show that within this kernel lies the essential structural relationship that is "environmental education."

\section{Metabolism is Learning}

Though hardly "simple," bacteria are considered by most biologists to be the simplest living organisms. In this section, I shall suggest that beginning with bacteria, the enacted organism/environment co-emergence generates information and learning. In establishing this dynamic polarity in a world that is otherwise deprived of it, life creates the conditions such that learning "from" one's environment (and from the things in it) becomes a possibility. With the self-constituting organization of the living, the organism gains a sort of ontological status not reducible to its underlying components, as Jonas argued was the true meaning of metabolism. This organization enables an organism to distinguish itself from its world but this distinction-making is not merely epistemological because it is the ongoing ground for the perpetuation of the living system. In the section that follows this one, I will show how the interactions made possible through this organism/environment coemergence become the basis for the varied forms of "environmental education" present across the biosphere.

In the previous section, I suggested that one of the most important insights in biology is the inadequacy of reductionistic explanatory strategies for even the properties of bacteria. The metabolism (i.e. the organism/environment exchanges that continually reconstitute the organism) of a bacterium reveal an organization that is unique when compared to most of the inorganic world. On the one hand, it has parts (biochemicals, genes, membranes, signalling molecules, etc.) that continually reconstruct the bacterium at each moment, seemingly satisfying the bottom-up causal structure of the world assumed under reductionistic explanation. However, at the same time, at each moment the capacity of these parts to metabolically reconstruct it is owed to the fact that the bacterium is organized in such a way that its parts' functions are constrained into doing so. This, on its own, is (perhaps) not strange. Indeed any composite structure constrains its parts in such a way that we can only understand the parts by appealing to how they are constrained by the whole (think of how hydrogen moves around space differently when paired up with oxygen (as water) then on its own). This is why Bechtel ${ }^{32}$ argues that mechanism is an improvement over reductionism, because it enables an explanatory framework based on simple causation while acknowledging that we live in the kind of a universe where organization puts constraints (and therefore new possibilities) upon its subcomponents.

Footnote 31 continued

environment interface is essential to what constitutes "nature" and "nurture," and these two terms are not prior to the interface itself.

32 Bechtel (2011). 
However, what makes the organization of a bacteria different from the organization of a water molecule is twofold. Organizationally, the bacterial cell is structured such that its whole and its parts are co-dependent on each other in a way that is not the case with a water molecule. With the water molecule, the individual atoms in no way owe their existence to the water molecule. In cells, the particular molecular configurations taken on are made possible (or likely) by the function of the cell as a whole, just as the organizational whole is possible only because of the presence of these particular components. This difference in organization distinguishes the type of constraints and possibilities that emerge in aggregates such as water molecules from circular systems such as bacteria cells. Juarrero ${ }^{33}$ calls these first-order and second-order contextual constraints respectively.

The second aspect that distinguishes a water molecule and a cell is informational. The cell recognizes and responds to differences. ${ }^{34}$ These differences are constituted by the organism because it is organizationally constrained in order to seek meaning and significance by comparing things. Organisms cannot register static states but they can compare states either in space (object A and object B at time C) or in time (object A at time B and time C). As Bateson pointed out, these differences are not locatable in the world itself. The nonorganic world (which Bateson called Pleroma) interacts and changes but in an immediate and quantitative manner. ${ }^{35}$ By contrast, every organism compares things and acts on the basis of what these comparisons signify for its purposes. In other words, information is constituted through the process by which the differences drawn out of these comparisons lead to different sorts of activity than would occur otherwise. It is important to understand how this differs, however, from a representationalist theory of mind. Difference-making is not accomplished by some homunculus first and then acted upon, but rather the perceptual distinction and the response to it are wrapped up together as the organism coordinates its ongoing relationship with its environment. Information is enacted. If life is a "mechanism" in the general way that Bechtel describes, it is certainly not by virtue of its being "machine-like" in the Newtonian sense that has permeated the metaphor since the beginning of the Industrial Age. If it is a "mechanism," it is one able to draw meaning from qualitative distinctions that it itself makes, responding to a world of signification and semiosis rather than only physical impacts and forces. ${ }^{36}$

However, the description of bacteria I have provided so far would seem to suggest that they could be hard-wired to constitute and respond to certain distinctions and that there is no flexibility, adaptation, or novelty present in this process. Were this the case, bacteria would not be a suitable foundation upon which to ground a theory of metabolism that enables adaptive learning and consequently novelty in relationships and behaviour. This is not, however, so. The environments that organisms constitute through their embodied activity are not laid out with unvarying affordances, as von Uexküll ${ }^{37}$ would imagine when he sought to map out the essential structure of other species Umwelten. Not only is bacteria

\footnotetext{
33 Juarrero (1999).

34 Bateson, Steps; Bateson, Mind and Life.

35 Of course, Bateson's dichotomy here is not exactly true. There are qualitative phase changes in states all through the universe, from water boiling to novel structures generated in dissipative systems at conditions far from equilibrium. Differences are registered differently even in some inorganic phenomena.

36 A fruitful area of research here is "categorical perception," which studies the ways in which phenomena which varies gradually and quantitatively from a physicochemical point of view are chunked and categorized into "types" by the organism acting towards them. The fact that $E$. coli can be tricked to swim towards a non-nutritive artificial sweetener indicates that categorical perception occurs in even prokaryotic organisms (Stjernfelt 2007).

37 von Uexküll (2010).
} 
able to register differences, they are also able to change their capacity to register differences. They are, for example, able to vary the threshold after which they respond to some stimuli, and do so in response to prior transactions with their environment. Sensitization and habituation are simple examples of how bacterial cells change their response to events, through respectively increasing or decreasing the registration of the event as a difference. Associative learning, the relaxing of the separation between two once uncorrelated events, has also been found to occur in bacterial colonies. ${ }^{38}$ Bacterial signal networks continually monitor and assess intracellular and external conditions with the organism adapting its physiology and behaviour accordingly. Such progressive distinguishing of qualities through teleologically-driven activity has been referred to as a "differentiation theory" of learning according to influential enactivist psychologists. ${ }^{39}$ These forms of learning also occur in the embodied experience of humans, which is backgrounded when learning focuses on the outcomes of symbols and propositions.

In bacteria, much of this communication system remains obscure. ${ }^{40}$ For example, it has only recently been discovered that, like eukaryotes, bacteria also have cytoskeletons, ${ }^{41}$ which are complex webs of microtubules that are continually built and discarded and which modify not only the structure of the cell but also its intraorganismic communication pathways. ${ }^{42}$ It seems that the cytoskeleton structure bears some important traits similar to the central nervous system in animals. The top-down organizing of neurons in the central nervous system, which are adjusted as the organism coordinates with its environment, seems to occur in parallel at the single-celled level. The particular organization and pathways of the cellular cytoskeleton are created and destroyed like neural pathways, as a result of the ongoing adaptive development of the cell to its environment. Not only are these dynamic structures absent in the static oval caricatures of single-celled organisms in high school biology textbooks, the fact that the organism changes the relationship between its parts (reconstructing its cytoskeleton, turning this gene on and that one off, producing more receptors of a certain type, etc.) as an integrative and information-constituting process, is hidden. Given the ongoing organismic readjustment of component parts by distinction-making activities, we see the concept of "mechanism" becoming increasingly problematic. Perhaps it is one day possible that a "mechanism" of the mind will be found. But the mechanistic metaphor will have been so contorted by that time that it will hardly be the case that we have wrestled the unruly appearance of life down and pinned its orderly and underlying causal structure. Indeed it is the very notion of mechanism that is transforming, becoming more organic and developmental, succumbing to the nature of life rather than explaining it.

We have a situation where the metabolism of an organism enables and is dependent upon systems-level, emergent properties including the capacity of the organism to create an organism/environment interaction, to constitute information about itself and its

\footnotetext{
38 Tagkopoulos et al. (2008) and Fernando et al. (2009) confirm associative learning in colonies of bacteria. It is still, as far as I can see, an insufficiently explored question whether a single bacterial cell is capable of associative learning. There are a number of means by which this could be possible, including through modifications of receptors, cytoskeleton structure, epigenetic alterations, the TCST system, or through integrated combinations of these and other systems. In any case, failure to find single-celled associative learning should not dismiss the relevance of multicellular bacterial learning activity, considering human learning is also generally considered a multi-cellular phenomenon.

39 Gibson and Pick (2003) and Gibson and Gibson (1955).

40 Galperin (2004).

41 Michie and Löwe (2006).

42 Gerhart and Kirschner (1997).
} 
environment through drawing distinctions, and to learn about itself and its environment by changing how it draws distinctions. Bacteria continually learn on the basis of what their needs, goals, and concerns are at the given moment. Indeed, it is this purposiveness that drives the whole process, leading the organism to enact an ongoing relationship with its internal and external environments, and driving the process of activity-led information creation and differentiation. In terms of learning, this means that the proximal goals it makes are altered as things in its environment change in significance, in service of whatever the organism's actual goals are at that time. Thus, how the environment appears and how the organism's genes operate are influenced by how information is constituted and changed. For example, the so-called information in the genetic code is constituted through how the genes are adjusted by the organism in response to how it responds to information elsewhere distributed across the organism/environment interaction. Because genomes are always within phenotypes (beginning with either the sperm or the non-fertilized eggs) that precede them, the genome is a resource with informational content constituted by the organism, not a recipe book for programmatically constructing the organism. In fact, it is the organism responding to environmental differences that draws distinctions within the genetic code to give it informational value which it would otherwise not have. This is why genes can be alternatively expressed and regulated, changing their "meaning" continuously and it is also why DNA floats inertly outside of a cellular context.

\section{Learning in Relationship}

So far, we have developed a concept of learning defined as the process by which an organism changes the way it distinguishes things in its environment, and that this process occurs through the ongoing organism/environment co-emergence that is metabolism. And, it would seem, learning is part of the metabolic process of all living beings down to prokaryotes that are themselves continuously adjusting the way they respond to things in accordance with whether and how those things have relevance for their ongoing interests and survival. In some sense, then, we can conclude that organismic metabolic activity enables them to disclose an environment that can educate them. While some may resist using the word "educate" for those situations where there is no "intention" to teach (whatever that means), it is now a common critical approach in education research to expose unintended or implicit lessons in classroom structure, teacher behaviour, and even the architecture of the school (more will be talked about this later, but for now, consider Eisner's "implicit curriculum", ${ }^{43}$ the "hidden curriculum" of Illich, ${ }^{44}$ and the idea of architecture as curriculum. ${ }^{45}$ Confining the use of the word educate to processes where we take "conscious" responsibility for the educating process polices the human/other species boundary only through also significantly restricting the range of human-human educational activities that are deemed pedagogically relevant. But the alternative, which is to retain one set of criteria for the term's scope in the case of humans and another for other species, commits an illogical (and perilous) anthropocentrism. The purpose of this section is to further my argument for restoring continuity between humans and the rest of the biosphere by showing how the metabolic activities enabling the organism to be educated also enable

\footnotetext{
43 Eisner (1994).

44 Illich (2000).

45 Orr (1994).
} 
the organism to educate its environment. In sections that follow, I will then explicitly deal with the reconfiguration of the term "environmental education" that I think is implied by the enactivist orientation and what implications lie in store for the way in which we go about educating humans.

Bacteria are not isolated entities in an otherwise inanimate world. There are other organisms there too. A bacterium is learning about an enacted world composed of things that are also learning about their own worlds. It is making distinctions about regularities and patterns of an environment where other things are making distinctions of their own. The distinctions that other things make lead to actions that that bacterium may then draw information from. While the learning activities of a bacterium in an inanimate environment already led to an interesting feedback loop (because the bacterium modified its behaviour based on what it learned, which in turn altered its relationship with its environment, and so on, eventually resulting in some sort of niche construction), ${ }^{46}$ things get quite a bit more complex when we have one thing learning about another thing that is learning about it. At this point, the feedback loop becomes co-constitutive. In fact, in the case of bacteria (as much as humans) this is where much of the most wondrous qualities of the organisms come out, such as the sorts of "population-level coordination" we find in bacterial quorum sensing, neural networking, temporary multicellularity, and associative learning. ${ }^{47}$ For example, in "quorum sensing," bacteria regulate their own and each other's activity through the production of signalling molecules, leading to varying degrees of integration that sometimes even takes the form of a multicellular organism.

We need to resist the urge to discount bacterial communication on the basis of whether or not we think the bacteria "intend" to communicate. This could side wind us into biological binaries (such as that between "signal" and "cue") in evolutionarily-adaptive explanations not helpful for this discussion. Even in the "sapient" human, novelty and richness in relationship depends upon a vast transactional flows running beneath the level of awareness, influencing and influenced by body language, tone of voice, unintended reactions to things that happen, and probably pheromones in what eludes conscious control.

Every organism is therefore capable of not only learning but of being learned from. And more significantly, whether aware of it or not, each also enters into that complex interorganismic world where what they may be learning about another may be in part a response from that other to some prior interaction with them. Here we have the instantiation of another form of relationality in the emergence of form in nature, an increasingly intimate and intertwined transaction made possible by the structure of the organism/environment relation in general but now introducing new degrees of possibility, distinction, but also communion. And of course, as complex organisms develop varied ways of interpreting each other, this relationality takes on many different forms of semiotic complexity. ${ }^{48}$ Our grammatically organized symbolic communication is one such relationality that emerges. ${ }^{49}$ And crucially for our pedagogical project is the fact that realizing that this

\footnotetext{
46 Odling-Smee et al. (2003).

47 Bacteria engage not merely in intra-species communication but in interspecies communication as well. For example, see Federle and Bonnie (2003).

48 Hoffmeyer (2008).

49 Some philosophers argue that a primitive cognition is indeed apparent in the sensorimotor coordination of simpler organisms but it is precisely "higher-order" cognition of the symbolic and representational type that sets humans apart from other species and is what requires explaining (Clark and Toribio 1994; Clark 1997). Although it is not my purpose to defend such a claim here, I find the arguments showing how all supposedly "higher order" cognition is also rooted in the body-in-transaction much more persuasive and urge the interested reader to explore this link further. Many thinkers, perhaps most famously (James 1890;
} 
relationality exists can alter the way in which we engage and the subsequent forms of relationality that come out of it.

An examination of the term "environmental education" is part of the reflexive reorganizing of epistemology that this paper ask for. Part of the work of a philosopher of education is to undertake this redefining. There is a lucky ambiguity in how the adjective in the phrase "environmental education" is often used. Although it is generally assumed to mean (roughly) the project of teaching people to learn about and engage responsibly with the larger world around them, it is also grammatically consistent to consider the term "environmental" as describing the manner by which education is conducted rather than a reference to its content. As such, a branch of environmental education ought to deal with what and how the environment teaches humans, where "environment" is taken to mean the biological and built environments, technologies, languages, and cultures that a person is immersed in, both within and outside the classroom. Because of this ambiguity, the term "environmental education" is ideally suited to describe the dual nature of the organism/ environment interface that is continually constituted through the organism's enacted relationships. An organism "teaches" its environment (which includes other organisms) while it is also taught by its environment. This is consistent with a recognition within environmental education scholarship and practice that it makes no sense to simply teach "about" the environment. Mediated experience must be combined with direct environment encounters and practices. For instance, we see this trend gaining prominence in approaches such as place-based education, ${ }^{50}$ experiential education, ${ }^{51}$ and interspecies pedagogy. ${ }^{52}$

I therefore suggest that environmental education is perhaps what all organisms do, continuously and variously, enabling not merely their individual survival but the development of relationships and sociality (which also means ecological communities) in all forms, from quorum sensing and multicellularity to human language. "Environmental education" is the ongoing re-creation of the relationship between organism and environment and the co-adaptation that occurs thereby. We are free to distinguish these processes, to draw distinctions between human-to-human transactions and those between humans and other species (as educational institutions have traditionally done), but doing so only cloaks the fact that these distinctions are themselves only possible through those broader educational interactions already established and variously elaborated upon through the evolution of metabolism. Saying that we teach and are taught by countless nonhuman beings is not, therefore, an extension of the scope of what is to be educationally considerable because education is not something that originated within and between humans only to be tentatively (and apparently 'generously') broadened out (or not) to consider others. Surely we distinguish self and other, or acting and undergoing, before we distinguish human and nonhuman, and surely we distinguish the difference between teaching and learning through the general enactive structure by which we are open to a world we are already learning about and being learned from. It may or may not be the case that humans are unique in "being aware" of the fact that they are "teachers" or "learners" in these processes. But it is to put the cart before the horse to assume that humans or any other species are only limited to interactions that they are aware of. As a result of such a punctuation, we have

Footnote 49 continued

Merleau-Ponty 1962), have worked on this problem (and more recently Lakoff and Johnson 1999; Wilson 2002; Johnson 2007).

50 Gruenewald (2003).

51 Blenkinsop (2011).

52 Affifi (2015). 
established a difference between other species and our own by assuming that only humanhuman relationships are considered educational (and by punctuating these in turn in what are generally linear rather than reciprocally enacted ways) and have built up institutions and professions to responsibly attend to the goals and prospects available through this way of seeing the world.

The ecological crisis is in part a result of our drawing certain distinctions and not others, with experiences, activities, and goals shaped accordingly. The capacity to recognize and respond to differences is basic to all living things, as I have argued, and it is up to us to now recognize what sorts of outcomes result from the distinctions we have drawn and now habitually assume. Redrawing these distinctions in order to cultivate better relationships is itself, by definition, one way of engaging in the process of "environmental education." This is clear once we realize that the epistemological process of distinction-making is performative, enactive rather than representational, and that our distinctions therefore have consequences for the learning relationships we are immersed in. To summarize the preceding discussion, an enactivist approach to "environmental education" recognizes that through new distinction-making we can repunctuate our experience such that we (1) are made aware that we are at all times educating those around us (and that we often modify these relations through becoming aware of them, (2) we are also aware that at all times being educated by the environment around us, and (3) learning and being learned from are recognized as ubiquitous across ecological communities, and (4) it is our pedagogical responsibility to consider to what extent we ought to engage in our relationships with other species as though they were learners as opposed to unvarying machines or substances regulated merely by chemical and energetic exchanges (as the biological reduction into physicochemistry would have it).

"Environmental education," as the metabolic process in all its varied and elaborated forms, also gives a new twist to understanding the evolution of life. The role of learning in evolution had for a long time been ridiculed, associated with the Lamarckian inheritance of acquired characteristics, however many current evolutionary biologists now put the adaptive, flexible, and responsive dimensions of organismic activity at the centre of their explanation of biological change. ${ }^{53}$ Baldwin was among the first to attempt to give a place to learning consistent with natural selection theory (and in particular the Weismannian rule that there be no direct genetic transfer of acquired traits to progeny) ${ }^{54}$ It is only in the past couple decades that Baldwin's insight has gained theoretical and empirical support. Learning (often disguised in jargon terms such as "phenotypic accommodation" or "developmental plasticity") is now increasingly seen as the activity of adjusting, trying out, or developing new organism/environment relationships, exploring new ecosystems, and biding time until genes catch up and enable the new behaviours to come about more easily or automatically. Such insights challenge the commonly held assumption that learning, if anything, slows the evolutionary process, insofar as it allows the organism to adapt to its context without requiring any genetic change. Contrary to a central tenet of the Modern Synthesis, a Baldwinian view suggests that genes are now seen as followers rather than leaders in the generation of evolutionary novelty. ${ }^{55}$ This is backed by widespread evidence that different genes can perform similar functions, and identical genes different functions (i.e. genocopies and phenocopies respectively) according to how they are coordinated into relationship by the transacting organism. Living beings are active agents participating in

\footnotetext{
53 Pigliucci and Müller (2010) and West-Eberhard, Developmental Plasticity.

54 Baldwin (1896).

55 West-Eberhard, Developmental Plasticity.
} 
and influenced by the environments that their very existences disclose, ${ }^{56}$ and what and how they learn from each other are not merely ecological issues but evolutionary issues as well. With this, we find "education" as a process stretching our far beyond what we originally envisioned, breaking down not only species boundaries but also the lines drawn between the history of culture and the vast temporality of biological evolution.

\section{Reinhabiting Habits}

Bacteria are much smaller and much less complex than even single-celled eukaryotes such as amoebas, paramecia, and human cells. They are invisible and so are often ignored, or are associated with disease and so are often hated. And yet, the Earth is predominantly organized and regulated by bacteria, from the oxygenation of the atmosphere to the nitrogen cycle, leading Gaia theory originator, Lynn Margulis, to exclaim that "[b]acteria initially populated the planet and have never relinquished their hold." ${ }^{57}$ On a smaller scale, developmental biologists reveal how microbial activity in the human gut alters our moods, dispositions, and drives, ${ }^{58}$ leading to the possibility that the motivation behind some of our educational endeavours may not be, in any simplistic sense, our "own." But what this paper has sought to explore is the notion that within the innovative metabolic adjustments of the world's tiniest organisms lie already the core of enactive learning between an organism and its co-emergent environment. These humble creatures reveal an interactive domain that remains the foundational organization of the varied ways in which learning has emerged in the evolution of life.

Recognizing the open-ended and relational nature of all organic relationships suggests that the disciplinary boundary between pedagogy and biology is a result of distinctionmaking that is not consonant with the enactive nature at root in the metabolic core of life. The open-endedness of all life suggests that we be concerned about the outcomes of these learning transactions. Unfortunately, recognizing a dualism is usually insufficient for transcending it, especially when we are immersed in human/environment transactions that support non-enactive conceptions of the nature of relationship (and here I am referring to those distinctions that we often consider essential and a priori rather than enacted, including subject/object, human/nature, cause/effect, freedom/determinism, teacher/student, etc.). We have our own habits, automated behaviours that push us away from conceiving and participating in the open-ended nature of the educational dimension of ecological communities. The educational organization of ecosystems needs to be uncovered such that we can sense and take responsibility for our ongoing performance within it, but existing technologies, language patterns, sociocultural values, and embodied habits all impinge on our capacity to read our current situation and mobilize accordingly. It is therefore naive to think that change begins or ends with the school curriculum. Ecologizing education requires nothing less than recognizing that ecologies are already educational, and

\footnotetext{
56 This view of evolution echoes Dewey's (1922) notion that automated behaviour (in the form of habits) is the result of experience, making regular patterns (which we associate with mechanism) the effect rather than the cause of biological activity. Repeatable, machine-like behaviour in living beings owes its existence to very different history than the lawlike phenomena in the physicochemical world. While the formal organization of life created the conditions for a sort of freedom and autonomy with respect to the regularity of efficient causality, the regularity in living beings turns out to be a way of economizing activity developed through transaction by an essentially indeterministic organism.

57 Margulis and Sagan (1995).

58 For a review, see Stilling et al. (2014).
} 
that all human activities from classrooms to farmers' fields are embedded in these larger pedagogical processes.

By admitting bacteria into the sphere of educational considerability, I hope to help pull some miseducative theoretical baggage off of the domain of life writ large, and clear the way for particular attention, response, and relationship with those varied enactive others, in city or in forest, of any species or genus. And yet, actual educative or miseducative interactions always involve particular beings. We therefore need to complement the general reconstruction of the scope of education with improved actual engagements with human and nonhuman learners. It is imperative, therefore, that we take a two-pronged approach: cultivating relationships with actual others through developing skills to silence our chattering and learn to listen to the nonhuman world, ${ }^{59}$ while also redrawing how we talk about biology, education, culture, and related concepts. In this vein, I'll end this paper with a warning to myself as much as to others. A seeming challenge lies ahead in dealing with the paradox of being difference-makers within the environmental education process. Humans punctuate the enactive structure of the organism-environment relationship by splitting it into subject and object, cause and effect, and the like, and the act of doing this enables us to identify "ourselves" as beings responsible for the outcomes of enacted organism-environment processes. This understanding then asks us to repunctuate experience to correct ways of thinking that led to undesirable results (such as detachment, anthropocentrism, hubris, instrumentalist thinking, etc.). It should be clear to readers that there is tension in this territory. On the one hand, we recognize that these epistemological splits reify ways of experiencing that foreground the human as causal agent and the rest of the environment as passive receiver of human actions. On the other, this very reification enables us to see that such reifications are problematic and in need of reform. The risk that emerges then is that accepting responsibility for "our" role in the transaction is itself reenforcing the very split we seek to remedy. In so doing, we place ourselves 'facilitating' the teacher-learner relationship, introducing an asymmetry even when we recognize the inherent bidirectionality of the learning interaction. We see ourselves in charge of challenging or reconstituting the subject-object divide. While such thinking can assist us in working towards an educational encounter that admits the environment (or its particular beings) as teacher, it also risks pushing the environment-as-teacher ever further away. I suspect only a deep and sustained practice of learning how to interact more sensitively with our varied relations will eventually enable other organisms to tell us when and where we ought to be teacher or learner, or both, or neither. Given the enactive nature of our own learning, it is impossible that any of our punctuations are "our own," as they will always be informed, consciously or otherwise, by the field of beings and processes that we are coemergent with. But without a culture of listening and responding, these punctuations remain only superficially joint collaborations. In this early stages, and in the depths of Western oblivion and fracture, we can for now point ourselves in these more generative and relational directions and initiate the practices consonant with such an enactive ecological view.

Open Access This article is distributed under the terms of the Creative Commons Attribution 4.0 International License (http://creativecommons.org/licenses/by/4.0/), which permits unrestricted use, distribution, and reproduction in any medium, provided you give appropriate credit to the original author(s) and the source, provide a link to the Creative Commons license, and indicate if changes were made.

${ }^{59}$ Blenkinsop et al. Shut-up and Listen: Implications and Possibilities of Albert Memmi's Characteristics of Colonization Upon "the Natural World" (2016). 


\section{References}

Affifi, Ramsey. 2015. Educating in a multispecies world. PhD, University of Toronto.

Affifi, Ramsey. 2011. What Weston's spider and my shorebirds might mean for Bateson's Mind: Some educational wanderings in interspecies curricula. Canadian Journal of Environmental Education 16: 46-58.

Baldwin, James M. 1896. A new factor in evolution. The American Naturalist 30(354): 441-451.

Bateson, Gregory. 1979. Mind and nature: A necessary unity. Toronto: Bantam Books.

Bateson, Gregory. 1972. Steps to an ecology of mind. New York, NY: Ballantine Books.

Bechtel, William. 2011. Mechanism and biological explanation. Philosophy of Science 78: 533-557.

Bitbol, Michel, and Pier L. Luisi. 2004. Autopoiesis with or without cognition: Defining life at its edge. Journal of the Royal Society Interface 1(1): 99-107.

Blenkinsop, Sean. 2011. Martin Buber: Dialogue, relationship, the other, and the more-than-human world. In Sourcebook of experiential education: Key thinkers and their contributions, ed. Thomas E. Smith, and Clifford E. Knapp, 48-55. New York, NY: Routledge.

Blenkinsop, Sean, Piersol Laura, Affifi Ramsey, Sitka-Sage, and Michael De Danann. 2016. Shut-up and listen: Implications and possibilities of albert memmi's characteristics of colonization upon the "Natural World". doi:10.1007/s11217-016-9557-9.

Bruner, Jerome S. 1961. The act of discovery. Harvard Educational Review 31(1): 21-32.

Clark, Andy. 1997. Being there: Putting brain, body, and world together again. Cambridge, MA: MIT Press.

Clark, Andy, and Josefa Toribio. 1994. Doing without representing. Synthese 101(3): 401-431.

Dewey, John. 1916. Democracy and education. New York, NY: MacMillan Company.

Dewey, John. 1922. Human nature and conduct. New York, NY: Henry Holt.

Eisner, Elliot W. 1994. The educational imagination: On the design and evaluation of school programs, 3rd ed. New York: MacMillan.

Federle, Michael J., and L. Bonnie. 2003. Interspecies communication in bacteria. Journal of Clinical Investigation 112(9): 1291-1299.

Fernando, Chrisantha, Anthony M.L. Liekens, Lewis E.H. Bingle, Christian Beck, Thorsten Lenser, Dov J. Stekel, and Jonathan E. Rowe. 2009. Molecular circuits for associative learning in single-celled organisms. Journal of the Royal Society Interface 6(34): 463-469.

Fodor, Jerry A. 1990. A theory of content and other essays. Cambridge, MA: MIT Press.

Galperin, Michael Y. 2004. Bacterial signal transduction networks in a genomic perspective. Environmental Microbiology 6(6): 552-567.

Gerhart, John C., and Marc W. Kirschner. 1997. Cells, embryos, and evolution: Toward a cellular and developmental understanding of phenotypic variation and evolutionary adaptability. Malden, MA: Blackwell Science.

Gibson, Eleanor J., and Anne D. Pick. 2003. An ecological approach to perceptual learning and development. Oxford: Oxford University Press.

Gibson, James J., and Eleanor J. Gibson. 1955. Perceptual learning: Differentiation or enrichment? Psychological Review 62(1): 32-41.

Gruenewald, David A. 2003. The best of both worlds: A critical pedagogy of place. Educational Researcher 32: $3-12$

Heschl, Adolf. 1990. L = C: A simple equation with astonishing consequences. Journal of Theoretical Biology 145: 13-40.

Hoffmeyer, Jesper. 2008. Biosemiotics: An examination into the signs of life and the life of signs. Scranton, PA: University of Scranton Press.

Illich, Ivan. 2000. Deschooling society. London: Marion Boyars Publishing.

James, William. 1890. The principles of psychology, vol. 2. New York, NY: Dover.

Johnson, Mark. 2007. The meaning of the body: Aesthetics of human understanding. Chicago, IL: University of Chicago Press.

Joldersma, Clarence. 2014. Neuroscience, education, and a radical embodiment model of mind and cognition. Philosophy of Education 2013: 263-272.

Jonas, Hans. 1966. The phenomenon of life: Toward a philosophical biology. Evanston, IL: Northwestern University Press.

Juarrero, Alicia. 1999. Dynamics in action: Intentional behavior as a complex system. Cambridge, MA: MIT Press.

Lakoff, George, and Mark Johnson. 1999. Philosophy in the flesh: The embodided mind and its challenge to western thought. New York, NY: Basic Books.

Lave, Jean, and Etienne Wenger. 1991. Situated learning. Legitimate peripheral participation. Cambridge: University of Cambridge Press. 
Luisi, Pier L., and Fransisco J. Varela. 1989. Self-replicating micelles-A chemical version of a minimal autopoietic system. Origins of Life and Evolution of the Biosphere 19: 633-643.

Margulis, Lynn, and Dorion Sagan. 1995. What is life?. Berkeley, CA: University of California Press.

Maturana, Humberto, and Fransisco J. Varela. 1980. Autopoiesis and cognition: The realization of the living. Dordecht: D. Reidel Publishing.

Merleau-Ponty, Maurice. 1962. Phenomenology of perception. London: Routledge.

Merleau-Ponty, Maurice. 1963. The structure of behavior. Pittsburgh, PE: Duquesne University Press.

Michie, Katherine A., and Jan Löwe. 2006. Dynamic filaments of the bacterial cytoskeleton. Annual Review of Biochemistry 75: 467-492.

Newell, Allen, and Herbert A. Simon. 1972. Human problem solving. New York, NY: Prentice-Hall.

Odling-Smee, John, Kevin N. Laland, and Marcus W. Feldman. 2003. Niche construction: The neglected process in evolution. Princeton, NJ: Princeton University Press.

Orr, David. 1994. Earth in mind. Washington, DC: Island Press.

Oyama, Susan. 2000. The ontogeny of information: Developmental systems and evolution, 2nd ed. Durham, NC: Duke University Press.

Piaget, Jean. 1974. Biology and knowledge: An essay on the relations between organic regulations and cognitive processes. Chicago, IL: University of Chicago Press.

Pigliucci, Massimo, and Gerd B. Müller (eds.). 2010. Evolution: The extended synthesis. Cambridge, MA: MIT Press.

Stewart, John, Olivier Gapenne, and Ezequiel A. Di Paolo (eds.). 2014. Enaction: Toward a new paradigm for cognitive science. Cambridge, MA: MIT Press.

Stilling, Roman M., Timothy G. Dinan, and John F. Cryan. 2014. Microbial genes, brain and behaviourEpigenetic regulation of the gut-brain axis. Genes, Brain and Behavior 13(1): 69-86.

Stjernfelt, Frederick. 2007. Diagrammatology: An investigation on the borderlines of phenomenology, ontology, and semiotics. Dordrecht: Springer.

Sumara, Dennis J., and Brent Davis. 1997. Enactivist theory and community learning: Toward a complexified understanding of action research. Educational Action Research 5(3): 403-422.

Tagkopoulos, Ilias, Yir-Chung Liu, and Saeed Tavazoi. 2008. Predictive behavior within microbial genetic networks. Science 320(5881): 1313-1317.

Thompson, Evan. 2007. Mind in life: Biology, phenomenology, and the sciences of mind. Cambridge, MA: Harvard University Press.

van Duijin, Marc, Fred Keijzer, and Daan Franken. 2006. Principles of minimal cognition: Casting cognition as sensorimotor coordination. Adaptive Behavior 14(2): 157-170.

Varela, Fransisco J. 1979. Principles of biological autonomy. New York, NY: North-Holland/Elsevier.

Varela, Fransisco J., Evan Thompson, and Eleanor Rosch. 1993. The embodied mind: Cognitive science and human experience. Cambridge, MA: MIT Press.

von Uexküll, Jacob. 2010. A foray into the worlds of animals and humans: With a theory of meaning. Minnesota, MN: University of Minnesota Press.

Vygotsky, Lev S. 1978. Mind in society: The development of higher psychological processes. Cambridge, MA: Harvard University Press.

West-Eberhard, Mary Jane. 2003. Developmental plasticity and evolution. New York, NY: Oxford University Press.

Weston, Anthony. 2004. Multicentrism: A manifesto. Environmental Ethics 2(1): 25-40.

Wilson, Margaret. 2002. Six views of embodied cognition. Psychonomic Bulletin and Review 9: 625-636.

Zahavi, Dan. 2005. Intentionality and experience. Synthesis Philosophica 20(40): 301-320. 